\title{
Phenotypic Characterisation of Candida Species from Clinical Isolates in a Tertiary Care Teaching Hospital Hyderabad, India
}

\author{
S. Swathi ${ }^{1}$, Taruni ${ }^{2 *}$, Rajkumar Sade $^{3}$ and Nagababu Pyadala ${ }^{4,5}$ \\ ${ }^{1}$ Department of Microbiology, MNR Medical College, Hyderabad, Telangana, India \\ ${ }^{2}$ Department of Microbiology, Government Medical College; Siddipet, Telangana, India \\ ${ }^{3}$ Department of Surgery, Kamineni Institute of Medical sciences, Narketpally, \\ Telangana State, India \\ ${ }^{4}$ Department of Clinical Research, Genomix CARL, Pullivendula, A.P., India \\ ${ }^{5}$ Department of Quality and Control, Genomix Molecular Diagnostics Pvt. Ltd., Hyderabad, \\ Telangana, India \\ *Corresponding author
}

\section{A B S T R A C T}

Background- Recently fungal infections are increased rapidly due to increase antibiotic use and misuse along with increased use of intravascular devices. Especially colonizing yeast like organisms like Candida species are emerging as important fungal pathogen. Aim-

Keywords

Candidiasis,

phenotypic

characterisation,

Candida species

Article Info

Accepted:

20 July 2018

Available Online:

10 August 2018
Thus this present study focused on isolation and characterisation of Candida species from various clinical isolates. Materials and methods- the present study was conducted in Department of Microbiology, ESI Medical College and Hospital from April 2017 to May 2018. Various clinical specimens included such as, urine, sputum, high vaginal swab, nail, skin and blood. A total of 1,650 specimens were included in this study. Identification and speciation of Candida isolates were done as per the standard Microbiological procedures. Results- Most of the Candida species was isolated from male patients (62.3\%) and 37.73\% were female patients. Most common age group affected by candidiasis was 21-40 years (28/52.8\%) followed by 41-50 years (14/25.9\%). Among all these specimens, urine culture yielded more number of Candida isolates $(27 / 50 \%)$ followed by sputum (14/25.9\%), high vaginal swab (6/11.1\%), nail (3/5.5\%), skin (2/3.7\%) and blood (2/3.7\%). Out of 54 isolates, one was Cryptococcus spp and rest of the isolates were Candida spp. Among 53 Candida species, 32 were isolated as Candida albicans (60.4\%), 8 were Candida tropicalis (15.09\%), 6 were Candida krusei (11.3\%) and 4 were Candida glabrata $(7.5 \%)$ and 3 were Candida parapsilosis (5.7\%). Conclusion- Identification and characterisation has to be done for all Candida isolates along with clinical correlation.

\section{Introduction}

Candidiasis is the most common fungal disease affecting skin, nails, mucosa and internal organs in human. It is caused by yeast like fungi Candida. It has wide clinical spectrum from acute to chronic and superficial to deep infection (Pfaller et al., 2006; Falagas, 2010; Jones, 1990). It is rarely found as primary infectious agent and mainly causes 
secondary infection in immunocompromised individuals. Multiple factors such as, diabetes mellitus, cancer, excessive use of antibiotics, increased use of intravascular devices can increase the risk of candidemia. Diversity and clinical spectrum among Candida species is wide (Prasad et al., 1999; John et al., 2001).

Therefore identification and speciation of Candida species is most important in clinical case management. Hence, the present study was aimed to isolate and speciation of various clinical isolates of Candida by using various phenotypic methods (Juliana, 2004; Marinho et al., 2010).

\section{Materials and Methods}

The Present study was held in the Department of Microbiology, ESI Medical College and Hospital, Hyderabad during the period of 1 year from April 2017 to May 2018. Various clinical specimens included such as, urine, sputum, high vaginal swab, nail, skin and blood.

A total of 1,650 specimens were included in this study. Identification and speciation of Candida isolates were done as per the standard Microbiological procedures (Duguid, 1989; Chander, 1995; Ajello and Hay, 1998; Koneman et al., 2005; Cooper, 1985; Perry and Miller, 1987; Rousselle et al., 1994).

\section{Results and Discussion}

A total of 1,650 specimens, 54 were isolated as yeast like growth. Most of the Candida species was isolated from male patients $(62.3 \%)$ and $37.73 \%$ were female patients (Figure 1). Most common age group affected by candidiasis was 21-40 years $(28 / 52.8 \%)$ followed by 41-60 years (14/25.9\%) (Figure $2)$. Among all these specimens, urine culture yielded more number of Candida isolates $(27 / 50 \%)$ followed by sputum (14/25.9\%), high vaginal swab $(6 / 11.1 \%)$, nail $(3 / 5.5 \%)$, skin $(2 / 3.7 \%)$ and blood (2/3.7\%) (Figure 3). Out of 54 isolates, one was Cryptococcus spp and rest of the isolates were Candida spp. Among 53 Candida species, 32 were isolated as Candida albicans (60.4\%), 8 were Candida tropicalis $(15.09 \%), 6$ were Candida krusei (11.3\%) and 4 were Candida glabrata $(7.5 \%)$ and 3 were Candida parapsilosis $(5.7 \%)$ (Figure 4).

Currently the opportunistic yeast infection has increased rapidly due to the global rise of immunocompromised individuals. There has been a significant increase in the number of superficial and deep yeast infections with both Candida albicans and non-albicans species worldwide (Hobson, 2003). The appropriate antifungal therapy is mostly depending on the proper identification of Candida spp. In this present study aimed to isolate and characterisation of various Candida spp from clinical specimens. Candidiasis can occur at all ages; a report from Mumbai indicated its highest incidence in the age group of 21-40 years (Dalal and Kelkar, 1980). These findings are in concurrence with those of ours, where we found highest number of Candida was obtained from the age group of 21-40 years (Figure 2).

The present study demonstrated male preponderance $62.3 \%$, a finding similar to that of Kashid et al., in which involvement was higher in males $(55.10 \%)$ as compared to the females (44.8\%) (Kashid et al., 2011). In this present study, Candida species were predominantly isolated from urine (50\%) followed by sputum (25.9\%), high vaginal swab (11.1\%), nail (5.5\%), skin $(3.7 \%)$, and blood $(3.7 \%)$. Our finding of higher number of isolation of Candida from urine is in agreement with many reports which have shown the increased incidence of Candida infection in the genitourinary tract in all areas of medical and surgical practice. 
Fig.1 Gender wise distribution of candidiasis patients

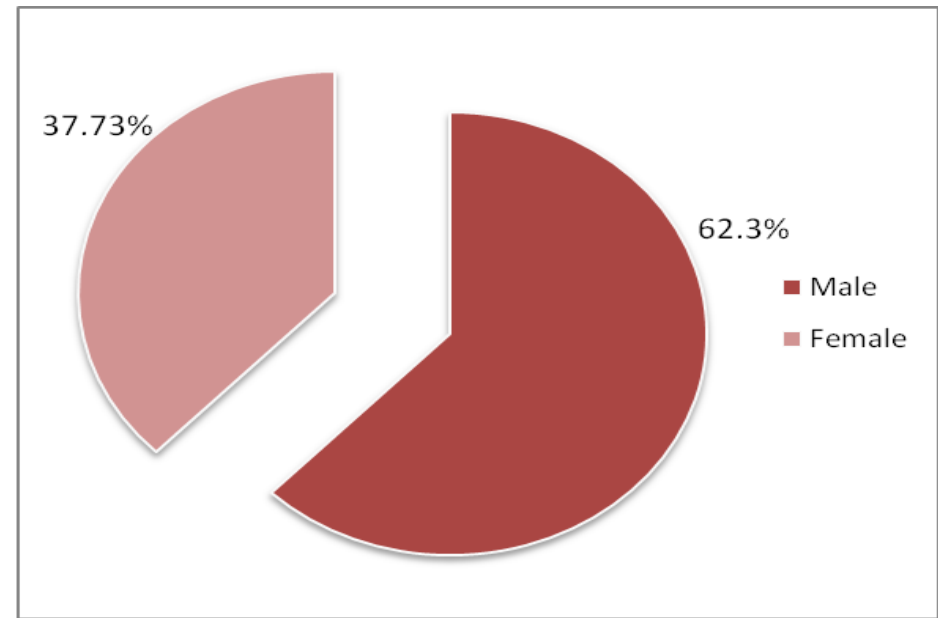

Fig.2 Age wise distribution of candidiasis patients

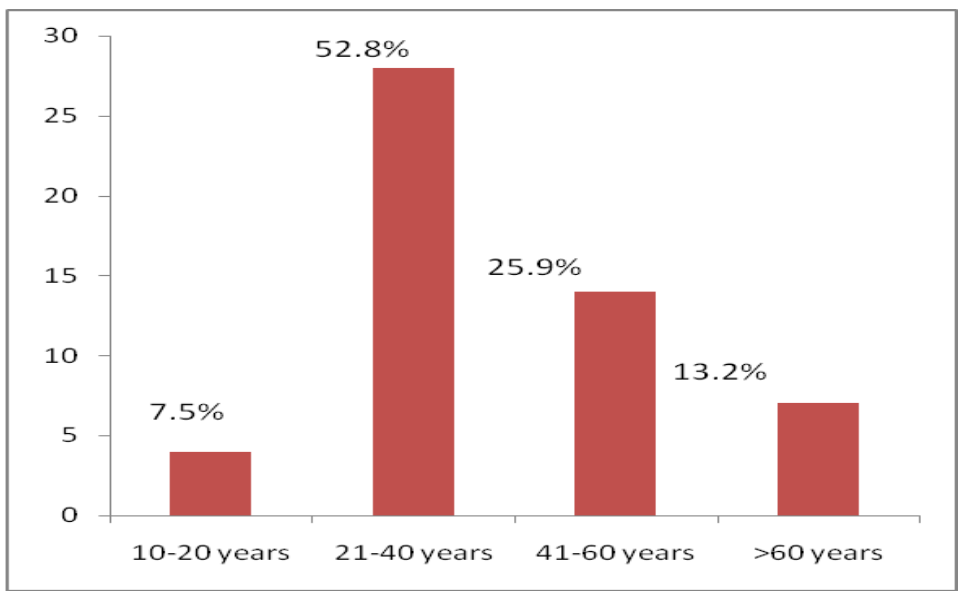

Fig.3 Distribution of Candida isolates in various clinical specimens

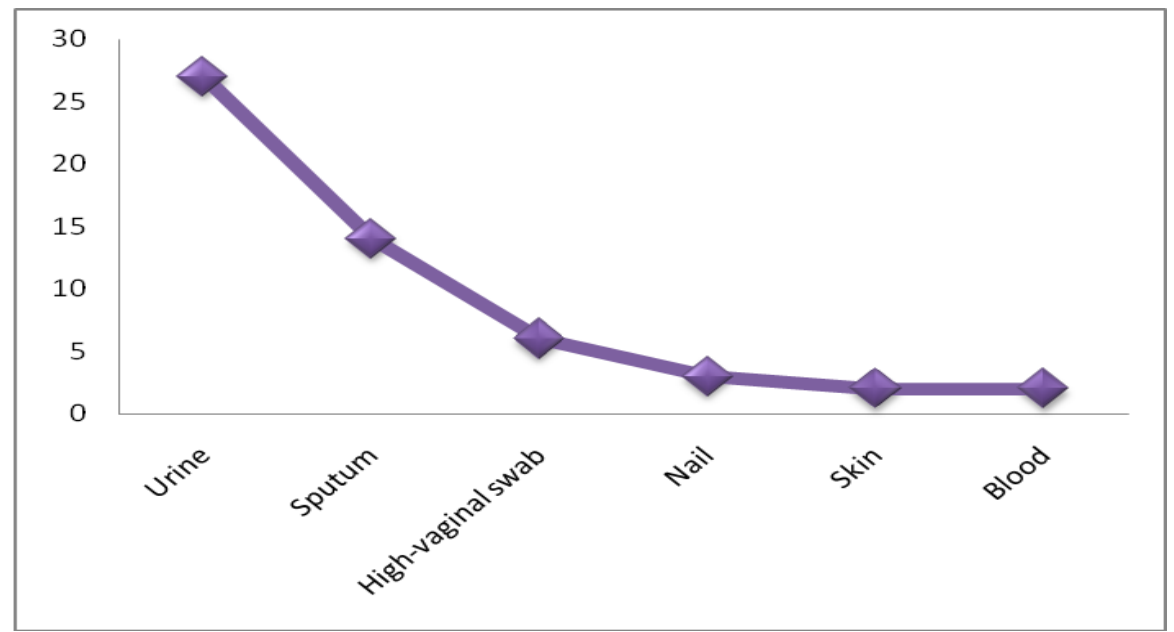


Fig.4 Identification and speciation of Candida isolates

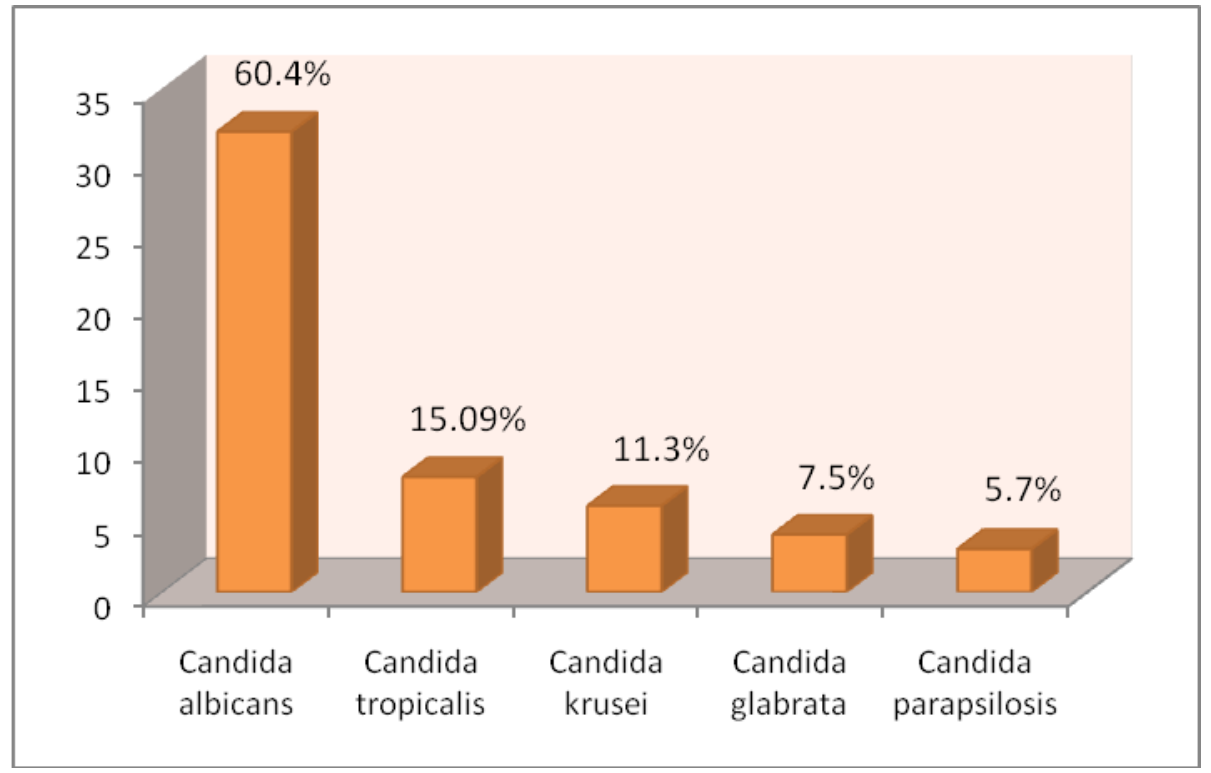

Candidal colonization of the urinary tract is common in patients with diabetes, patients receiving broad-spectrum antibiotics or immunosuppressants, or those with long term urinary catheters (Dharwad and Dominic, 2011; Mohandas and Ballal, 2011; Basu et al., 2011). Candida is a normal inhabitant of the mouth and can be recovered from sputum in 20 to 55\% of normal subjects (Malini, 2000). The role of Candida in pulmonary candidiasis and its diagnosis is still controversial. Isolation of Candida species from respiratory specimens is frequent in mechanically ventilated patients. Respiratory samples constituted $25.9 \%$ of sources of Candida in our study. Candida species have been found to be one of the most common pathogens causing blood stream infections (Chander, 1995). Nevertheless in our study, only two Candida isolate were obtained from blood specimen. Candida albicans was the commonest species isolated in our study, which accounts for $60.4 \%$ of the total isolates. Our study report was correlated with other study done by (Sengupta et al., 1999). (Kangogo et al., 2011) study reported $86.7 \%$ were of C. albicans, whereas $13.3 \%$ were non albicans Candida (Kangogo et al., 2011).
According to Zaini et al., study, $63.5 \%$ were isolated as C. albicans and $36.5 \%$ as non albicans Candida (Zaini et al., 2006). The predominance of Candida albicans in this study may be due the clinical specimens obtained from hospitalized patients of prolonged hospital stay, pregnancy or catheterised individuals. Among the 21 Candida non- albicans, $C$. tropicalis (15.09\%) was the most common species isolated in our study. A study done by Basu et al., reported $C$. tropicalis in a similar frequency followed by $C$. krusei and $C$. glabrata (Malini, 2000).

Opportunistic fungal infections are increasing rapidly due to the rising of immunocompromised individuals globally. Therefore, early detection of clinically significant yeast infections are necessary to chose a proper antifungal treatment. There is need of further study with large number of specimens and clinico-epidemiological correlation to understand the prevalence, aetiopathogenesis of opportunistic fungal infections in our community.

Conflict of interest - None 


\section{References}

Ajello L, and Hay RJ. Candidiasis. In: Collier L, Ballows A, Sussman M. 9th edition. Volume 4, Medical Mycology; Topley $\&$ Wilson's microbiology and microbial infections. Hodder Arnold; 1998; p. 442-46.

Basu S, Gugnani HC, Joshi S, Gupta N. Distribution of Candida species in different clinical samples. J Glob Infect Dis. 2011; 3: 40-45.

Chander J. Candidiasis. In: A text book of Medical Mycology. New Delhi: Mehta Publishers, 1995; p. 266-90.

Cooper, Silvo-Hunter. In: Lennette, Balows, Hausler. Manual of Clinical Microbiology. Washington: ASM, 1985.

Dalal PJ, and Kelkar SS. Clinical patterns of Candida infections in Bombay. Indian $J$ Dermatol Venereol Leprol. 1980; 46(1): 31-32.

Dharwad S, and Dominic RMS. Species identification of Candida Isolates in Various Clinical Specimens with Their Antifungal Susceptibility Patterns. Journal of Clinical and Diagnostic Research. 2011; 5(6) Suppl-1: 1177-81.

Duguid J. Fungi. In: Mackie and McCartney. Practical medical microbiology. London: Churchill Livingstone, 1989; p. 675-99.

Falagas ME, Roussos N, Vardakas KZ. Relative frequency of albicans and the various non-albicans Candida spp among candidemia isolates from inpatients in various parts of the world: A systematic review. Int $\mathbf{J}$ Infect Dis 2010; 14: e954-66.

Hobson RP. The global epidemiology of invasive Candida infections-is the tide turning? J Hosp Infect. 2003; 55: 15968.

John H, Rex JH, Michael A. Antifungal Susceptibility Testing: practical aspects and current challenges. Clin Microbiol Rev. 2001; 14: 643-58.

Jones JM. Laboratory Diagnosis of invasive candidiasis. Clin Microbiol Rev. 1990; 3: $32-45$

Juliana CR. Phenotypic and Genotypic Identification of Candida spp. isolated from hospitalized patients. Rev Iberoam Micol. 2004; 21: 24 - 28.

Kangogo MC, Wanyoike MW, Revathi G, Bii CC. Phenotypic characterization of Candida albicans from clinical sources in Nairobi, Kenya. African Journal of Health Sciences. 2011; 19(3): 19-23.

Kashid RA, Belawadi S, Devi G. Characterization and antifungal susceptibility testing for Candida species in a tertiary care hospital. JHSR. 2011; 2(2): 1-7.

Koneman EW, Allen SD, Janda WM, Schreckenberger PC, Winn WC. In: Color atlas and textbook of diagnostic microbiology. New York City: Lippincott Williams and Wilkins, 2005; p. 1543-552.

Malini VD. Characterization and antifungal susceptibility of Candida spices. A Preliminary study. Journal of Academy of Clinical Microbiologists. 2000; 2: 5557.

Marinho S, Teixeira AB, Santos OS, Cazanova R. F., Ferreira. Identification of Candida spp. by phenotypic test and PCR. Braz J Microbiol. 2010; 41: 28694.

Mohandas V, and Ballal M. Distribution of Candida Species in different clinical samples and their virulence: Biofilm formation, proteinase and phospholipase production: A study on hospitalized patients in Southern India. J Glob Infect Dis. 2011; 3(1): 4-8.

Perry JL, and Miller GR. Umbelliferyllabeled galactosaminide as an aid in identification of Candida albicans. $J$ 
Clin Microbiol. 1987; 25(12): 24242425

Pfaller MA, Papas PG, Wingard JR. 2006. Invasive fungal pathogens: current epidemiological trends. Clin. Infect. Dis. 43(Suppl. 1): S3-S14.

Prasad KN, Agarwal J, Dixit AK, Tiwari DP, Dhole TN, Ayyagari A. Role of yeasts as nosocomial pathogens and their susceptibility to fluconazole and amphotericin B. Indian J Med Res. 1999; 110: 117.

Rousselle P, Freydiere A, Couillerot P, Montclos H D, Gille Y. Rapid identification of Candida albicans by using Albicans ID and fluoroplate agar plates J. Clin. Microbiol. 1994; 32(12): 3034-036.

Sengupta P, and Ohri VC. Study of yeast species isolated from clinical specimens. Medical Journal Armed Forces India. 1999; 55: 319-21.

Zaini F, Shoar MG, Kordbacheh P, Khedmati E, Safara M, Gharaeian N. Performance of Five Phenotypical Methods for Identification of Candida Isolates from Clinical Materials. Iranian $J \mathrm{Publ}$ Health. 2006; 35(1): 25-32.

\section{How to cite this article:}

Swathi, S., Taruni, Rajkumar Sade and Nagababu Pyadala. 2018. Phenotypic Characterisation of Candida Species from Clinical Isolates in a Tertiary Care Teaching Hospital Hyderabad, India. Int.J.Curr.Microbiol.App.Sci. 7(08): 3849-3854. doi: https://doi.org/10.20546/ijcmas.2018.708.394 